\title{
Conference report ESRC seminar series: trans-sectoral partnerships, sustainability research and the oil and gas industry in Russia
}

\author{
Emma Wilson
}

Notes on Seminar 1: 'Sustainable Community Development, Social Impact Assessment and Anthropological Expert Review' (26 November 2004, Scott Polar Research Institute, Cambridge) and Seminar 2: 'A Sustainable Future for Sakhalin Island?' (9 March 2005, Leicester University)

\section{Seminar series aims}

The oil and gas industry has immense significance for global security. With recent geopolitical developments, international attention is turning to Russia's oil and gas potential, which is taking on ever more strategic importance. Local governments and communities face new environmental and social challenges related to oil and gas development in areas of particular ecological sensitivity. Corporate engagement with NGOs, communities and local authorities can be hampered by a lack of mutual understanding and in-depth, locally grounded analysis. This ESRC seminar series has been designed to provide a neutral forum for dialogue between academia, industry, government and civil society, and to facilitate a critical examination of Western and Russian approaches to sustainable development and corporate governance in Russia. The seminar series is being organised by the Scott Polar Research Institute, Cambridge (Dr Florian Stammler and Dr Piers Vitebsky), Leicester University (Professor 
Mike Bradshaw) and the London School of Economics' Centre for Environmental Policy and Governance (Dr Andy Gouldson); with overall co-ordination provided by Dr Emma Wilson, director of Environment \& Community Worldwide (ECW) and associate of the Scott Polar Research Institute. The seminar series is sponsored by the Economic and Social Research Council (ESRC), with some additional support from ECW and British Petroleum (BP). Seminar programmes and speakers' presentations can be viewed on the respective seminar series websites at http://www.spri.cam.ac.uk/events/russianoil/ and http://www.le.ac.uk/geography/intro/ESRCresearchseminars.html

\section{Seminar 1}

26 November 2004, Scott Polar Research Institute, Cambridge University 'Sustainable Community Development, Social Impact Assessment and Anthropological Expert Reviem'

The aims of the first seminar were (a) to facilitate a discussion of the sustainable development concept in the context of the oil and gas industry in Russia from the academic and corporate perspectives and (b) to explore the ways that local communities, government, NGOs and industry engage with one another in the pursuit of sustainable development goals. In the community development discussion, the aim was to discuss the effectiveness of various impact assessment processes, community engagement models and sustainable development initiatives for local communities. The 39 participants included representatives of industry, NGOs, independent consultants and academics, and five guest speakers from Russia. Eleven post-graduate students attended, their costs where necessary being covered by ESRC.

The first seminar opened with an introduction to the sustainability concept from the academic and corporate perspectives and included discussion of what sustainable development means in the Russian context. The role of international financial institutions (IFIs) was noted as being important for controlling the activities of resource extraction companies, although not a universal solution, as companies who do not take credit from IFIs are not subject to this kind of control. There are also many gaps between IFI guidelines and Russian legislation, which make the former difficult to implement in Russia. Participants recognised the need to influence not only companies at the project level, but also governments at the policy level. Significant factors in shaping Russia's sustainable development policy were highlighted, including Russia's role within global sustainable development frameworks (e.g. Kyoto Protocol), the powerful domestic 'resource utilisation' lobby, and the significance of hydrocarbon extraction for the national economy over the short to medium term. The lack of coherent policy and poor implementation are hindrances to sustainable development in practice. Participants also noted the need for more mutual understanding (e.g. between companies, investment banks, local governments and communities) to bridge the divide between local and Western understandings of what sustainable 
development should be in practice. Participants suggested the need to move away from 'procedures' and focus on 'outcomes': 'participation' often serves to legitimate rather than transform behaviour. A key question is therefore how to translate stakeholder engagement into positive influence and change.

The second session focused on project impact assessments and the need to develop appropriate legal frameworks and ensure the effective implementation of the legislation that currently exists. Participants acknowledged the importance of carrying out strategic assessment of cumulative impacts of multiple oil and gas developments, such as those taking place currently on Sakhalin Island. Longterm regional development plans are necessary for regions, especially for indigenous populations living within those regions. Recommendations were made on how legislation relating to the Anthropological Expert Review (etnologicheskaya ekspertiza) process can be improved. The Social Impact Assessment (SIA) process was examined and some comparison made with the Anthropological Expert Review process. Participants emphasised the need to ensure effective representation during public consultation and to ensure that the information from social impact studies translates into change within a company. Participants considered how much common ground there is between ecological and ethnic interest groups and what kind of conflicts there might be between environmental protection and human rights priorities, both of which need economic justification.

The final session provided an opportunity to examine case studies of engagement between local communities and oil companies. The case studies provided examples of how people can work together in the absence of a complete legal framework. Individual agreements between indigenous land users and oil companies were shown to be effective as a way to 'fill in the gaps' until official regulation is established. Long-term personal relations between oil company workers and reindeer herders can create a positive climate of co-existence between companies and communities. The Nenets Autonomous Region case demonstrated how an indigenous association is building relations by establishing a working group with local oil companies and promoting legislative reform by drafting regional-level laws. The Sakhalin case study demonstrated how local awareness has increased in recent years and oil companies have sponsored some successful community development initiatives. However, successful engagement can be hampered by sundry social factors: a lack of trust on the part of local populations; misrepresentation of local interests by charismatic figures in the community; a company's poor preparation for consultations; and the self-interest of companies and local administrations. Participants noted that there is not always a conflict between local communities and development, but that there are problems working out how to integrate hunters, herders and other resource users into an industrialising society. Local people want to be employed on their own terms using their own language and skills. Mixed blood settlers also feel a connection to place, although ethnic rights tend to be seen in terms of indigenous peoples, not mixed communities.

Recommendations from participants included ongoing public consultation focusing on direct engagement with potentially impacted natural resource users. 
Small, focused meetings in seasonally appropriate places - such as the ongoing Sakhalin Energy meetings with reindeer herders - are often more effective than large public meetings. Engagement with local-level as well as regional-level regulatory agencies is recommended. Transparency and accountability were called for in all compensation payments. Effective management of the activities of contractors and subcontractors was identified as critical to project success and community wellbeing. Project operators and Western contractors need to ensure a good knowledge of Russian legislation in order to write up good contracts for local employees and companies. There was a lot of positive feedback from the event. Participants noted that there had been a high level of discussion with a clear focus, a good range of participants around the discussion table. While the seminar achieved a broad diversity of participation, the absence of (Russian or other) government representatives was noted by participants. Participants had not been afraid to discuss 'hot topics' and these were discussed in a constructive way. It was felt that the seminar had moved the public and academic debate on these issues forward. The case studies (Sakhalin, Yamal, Nenets) were found to be particularly interesting and useful.

\section{Seminar 2}

9 March 2005, Department of Geography, Leicester University, 'A Sustainable Future for Sakhalin Island?

The aims of the second seminar were (a) to explore issues related to sustainability and oil and gas development on Sakhalin Island; and (b) to provide a neutral forum for debate of the broad range of issues related to sustainable development in the context of multinational oil and gas projects in this region, avoiding the emotional tone of current debates surrounding these developments as they are portrayed in the media and by some international NGOs. The seminar was attended by approximately 35 participants, including representatives of industry, government, academia, NGOs and local communities. Five participants came from Sakhalin Island itself, including two speakers, representing the regional government and a local NGO respectively, and local representatives of BP, Rosneft and a local community. Another speaker from Washington DC represented a US-based NGO working on Russian Far Eastern issues. Government representation was also boosted by a participant from the UK Department for International Development (DfID). The seminar opened with a presentation from Professor Mike Bradshaw, head of the Leicester University Geography Department, who provided a comprehensive overview of the Sakhalin oil and gas projects, set in the regional and global geo-political context. Key power relations are between the centre and the region, but increasingly the local-global dynamic is playing a role, particularly in terms of NGO engagement with oil companies and financial institutions.

A key issue for stakeholder engagement is building trust and understanding between stakeholders through informed debate, and the need for neutral forums 
for debate, such as this seminar series. With regards to oil company consultations, it was noted that efforts have been made by companies to move beyond standard public consultations, for example the Sakhalin Energy consultations with reindeer herders (reported in Seminar 1). However, public consultations are still considered 'contrived' in some cases. Participants were interested to hear about the role of oil company community liaison officers (CLOs), who live and work in local communities and provide a channel for local concerns about project activities. To work effectively, these local company representatives need to have the authority to facilitate change in the behaviour of companies and contractors. NGOs claim that information is often concealed by companies. Accurate information is also needed about community dynamics and politics in order for companies to understand the complexities of community actions such as the recent indigenous peoples' protest. 'Social investment' in the form of grants by oil companies may also create splits in a local community rather than leading to sustainable development outcomes. Ethnographic research can inform the work of oil companies helping them better to understand these complexities.

Participants discussed the controversial nature of the Sakhalin I and II project Production Sharing Agreements and recent legislative changes, which mean Sakhalin will receive few benefits especially after 2007, and the role of international financial institutions in enabling stakeholders to exert a certain amount of control over project development. Doug Norlen (Pacific Environment) emphasised the need for companies to employ global best practice and not to hide behind the corporate ALARP standards ('as low as reasonably practicable'). Participants noted that while NGOs and the media are important channels for stakeholder messages, there is a danger that in the international media (e.g. the Western Pacific grey whale) some messages get more coverage than others do. Companies tend to treat these big international issues with more attention, which means that less attention might be paid to issues that are more important to local populations and sustainable development, but are unable to attract the same kind of emotional response internationally.

The second session was an opportunity for local Sakhalin stakeholders to present their own views and engage in debate. Vladimar Bida (Sakhalin Administration) provided valuable context for the debate, highlighting efforts made to balance economic interests (employment, investment) with environmental and social needs of populations (social security, waste management and oil spill response). Dr Bida noted the assistance of the European Bank for Reconstruction and Development (EBRD) in some of these goals. Participants noted the need for Sakhalin to strike a balance between renewable and non-renewable resource use, and Bida drew attention to efforts being made by the Administration, including development of fish hatcheries and timber processing ventures. Dmitry Lisitsyn (NGO Sakhalin Environment Watch) addressed many specific environmental and social issues and recommended solutions, the results of over 10 years of close local monitoring and research. A key issue for sustainable development on Sakhalin is the fishing industry and protection of the fish resources and their habitat, in particular the rivers that are to be crossed by the Sakhalin I and II 
project pipelines. The local NGO presentation showed photographs of severe erosion in some areas of Sakhalin where pipelines are currently being laid. These were compared to Alaska's above-land pipeline systems, which it was suggested would be more appropriate to the Sakhalin landscape. Similarly, Lisitsyn suggested that waste from Sakhalin II project activities in the south be dumped further from the sensitive waters of Aniva Bay where it is currently proposed. Lisitsyn discussed the use of project revenues and bonuses, and commented that despite mismanagement of these revenues in the past and consequent lost opportunities, he is more optimistic about the future with the new administration that is now in power. A key challenge would be to encourage all companies to provide the necessary information to complete cumulative impact studies. The involvement of the regional administration would be pivotal, and is already involved in monitoring of all the projects and will continue to do so.

The seminar was a rare opportunity to get diverse stakeholders round the discussion table to discuss a whole range of sustainable development issues. The absence of Sakhalin Energy and the European Bank for Reconstruction and Development were regretted, as they had been unable to respond to criticisms or comment on potential opportunities. Once again, the seminar provided participants with plenty of good networking opportunities. The third seminar in this series will take place in June 2005 (date to be confirmed), hosted by the Centre for Environmental Policy and Governance at the London School of Economics. For more information about the third seminar and to have your name included in the seminar series mailing list, please contact Emma Wilson at ecw@ecworldwide.co.uk. 